Article

\title{
Bioconversion of Waste Fiber Sludge to Bacterial Nanocellulose and Use for Reinforcement of CTMP Paper Sheets
}

\author{
Genqiang Chen ${ }^{1,2}$, Guochao Wu ${ }^{2}{ }^{(D)}$, Björn Alriksson ${ }^{3}$, Wei Wang ${ }^{1}$, Feng F. Hong ${ }^{1, *}$ and \\ Leif J. Jönsson ${ }^{2, *}$ \\ 1 College of Chemistry, Chemical Engineering and Biotechnology, Donghua University, Shanghai 201620, \\ China; chengenqiang@gmail.com (G.C.); wangv@dhu.edu.cn (W.W.) \\ 2 Department of Chemistry, Umeå University, Umeå SE-901 87, Sweden; guochao.wu@umu.se \\ 3 RISE Processum AB, SE-891 22 Örnsköldsvik, Sweden; bjorn.alriksson@processum.se \\ * Correspondence: fhong@dhu.edu.cn (F.F.H.); leif.jonsson@umu.se (L.J.J.); \\ Tel.: +86-21-6779-2649 (F.F.H.); +46-90-786-6811 (L.J.J.)
}

Received: 1 August 2017; Accepted: 14 September 2017; Published: 18 September 2017

\begin{abstract}
Utilization of bacterial nanocellulose (BNC) for large-scale applications is restricted by low productivity in static cultures and by the high cost of the medium. Fiber sludge, a waste stream from pulp and paper mills, was enzymatically hydrolyzed to sugar, which was used for the production of BNC by the submerged cultivation of Komagataeibacter xylinus. Compared with a synthetic glucose-based medium, the productivity of purified BNC from the fiber sludge hydrolysate using shake-flasks was enhanced from 0.11 to $0.17 \mathrm{~g} /(\mathrm{L} \times \mathrm{d})$, although the average viscometric degree of polymerization $\left(D P_{\mathrm{v}}\right)$ decreased from 6760 to 6050 . The cultivation conditions used in stirred-tank reactors (STRs), including the stirring speed, the airflow, and the $\mathrm{pH}$, were also investigated. Using STRs, the BNC productivity in fiber-sludge medium was increased to $0.32 \mathrm{~g} /(\mathrm{L} \times \mathrm{d})$ and the $D P_{\mathrm{v}}$ was increased to 6650. BNC produced from the fiber sludge hydrolysate was used as an additive in papermaking based on the chemithermomechanical pulp (CTMP) of birch. The introduction of BNC resulted in a significant enhancement of the mechanical strength of the paper sheets. With 10\% $(w / w)$ BNC in the CTMP/BNC mixture, the tear resistance was enhanced by $140 \%$. SEM images showed that the BNC cross-linked and covered the surface of the CTMP fibers, resulting in enhanced mechanical strength.
\end{abstract}

Keywords: bacterial cellulose; fiber sludge hydrolysate; stirred-tank reactor; chemithermomechanical pulp; paper sheet; tensile strength; tear resistance

\section{Introduction}

Bacterial nanocellulose (BNC) is mainly synthesized by acetic acid bacteria. As plant cellulose, BNC is an unbranched polymer composed of $\beta-1,4$-linked glucopyranose residues. However, BNC has much higher crystallinity and a higher degree of polymerization than plant cellulose $[1,2]$. The diameter of the BNC fiber, ranging from 20 to $80 \mathrm{~nm}$, is smaller than that of other natural or synthetic nanofibers. BNC features many other important unique properties, including high purity, high wet tensile strength, a high Young's modulus, a large water-holding capacity, good shape maintenance, and excellent biocompatibility. These properties endow BNC with great potential in the areas of textile manufacturing, fiber-based paper and packaging products, food industry, biomedical materials, and advanced functional bionanocomposites [1,3,4]. However, these applications of BNC are restricted by its relatively high price. The high price is due to the high cost of the culture medium and the low productivity and yield of cellulose obtained in slow-growing static bacterial cultures [5-7]. 
To lower production costs, previous investigations have addressed production of BNC in static cultures from agro-industrial by-products and cellulosic residues such as konjak glucomannan [8], wheat straw [9,10], waste fiber sludge [11], spruce hydrolysate [12], and waste cotton textile [13,14]. Fiber sludge is a residual material obtained from pulp mills and biorefineries. It is usually relatively easy to hydrolyze fiber sludge enzymatically without prior thermochemical pretreatment, which is advantageous, as pretreatment usually results in formation of substances that inhibit the bacterium. Commonly-used bacterial strains are sensitive to well-known inhibitory compounds formed during pretreatment, except the aliphatic carboxylic acids $[15,16]$. Interestingly, it has been reported that fiber sludge hydrolysate could be used to produce BNC with the strain Komagataeibacter xylinus (formerly Gluconacetobacter xylinus) ATCC 23770 (American Type Culture Collection, Manassas, VA, USA) in static cultivation [11]. However, the possibility of submerged production of BNC from fiber sludge has not been examined.

To promote production of BNC, submerged cultivation in STRs (stirred-tank reactors) has been proposed as a possibility $[17,18]$. Compared with traditional static bacterial cultures, submerged cultivation in STRs would be less labor intense, allow higher glucose consumption rate and productivity, and facilitate scale-up. In the field of production of BNC in STRs, a few studies have been conducted with regard to cultivation conditions, such as medium $\mathrm{pH}$, dissolved oxygen (DO), stirring speed, and concentration of culture medium components [19-21]. In addition, several other studies have been done on the structure of the STR; for example, comparisons of different impellers, and the introduction of a spin filter to the vessel $[17,22]$. However, these studies were focused on the productivity of BNC and rarely considered the effects of stirring on the structure and properties of the BNC, which would be significant if the $\mathrm{BNC}$ would be used for making materials.

Previously, BNC has been employed as an additive in cotton lint pulp and kraft pulp of birch and pine, or as a coating material for print paper, or produced as special paper (such as a diaphragm of electroacoustic transducer and electronic paper). It was reported that BNC could enhance the mechanical strength and other paper properties (such as gloss value, trend to yellowing), though the detailed mechanism has not been studied [23-30]. Chemithermomechanical pulp (CTMP) is widely produced around the world, due to its high product yield in the manufacturing process. However, because of the relatively high lignin content in the CTMP, it is also characterized as being weak in mechanical strength, which means there is a demand for enhancement of the properties of CTMP-based paper products on the market.

In this work, we addressed the problems of how to bio-convert waste fiber sludge into BNC in an STR and the benefits of including BNC in papermaking with CTMP. The study was started by employing a bacterial strain of $K$. xylinus that could produce BNC with high productivity and high $D P_{\mathrm{v}}$. Then, we investigated the possibility to produce $\mathrm{BNC}$ from fiber sludge hydrolysate, the effects of several parameters of cultivation in STRs on the BNC productivity and the $D P_{\mathrm{v}}$, and finally the effects of BNC on the mechanical properties of CTMP-based paper sheets.

\section{Materials and Methods}

\subsection{Microorganism and Chemicals}

A strain of K. xylinus (DHU-ZGD-1186) was kindly offered by Hainan Yeguo Foods Co., Ltd., Haikou, China, and was maintained in a glycerol stock at $-80{ }^{\circ} \mathrm{C}$. The glucose was of spectral grade. The peptone was from Merck KGaA (Darmstadt, Germany). The yeast extract was from VWR Chemicals (Radnor, PA, USA). Deionized water was used in all the experiments. The sulfite fiber sludge was cellulosic waste from the Domsjö Fabriker wood biorefinery in Örnsköldsvik, Sweden. Enzymatic hydrolysis of the fiber sludge was performed in a 75-L (working volume) bioreactor equipped with an anchor impeller (Gustav-Pilot Series, Belach Bioteknik, Stockholm, Sweden). Twenty kilograms dry-matter content (sulfite fiber sludge) and $10 \%$ (10 g/100 g dry sulfite fiber sludge) loading of a liquid enzyme preparation (Cellic CTec2, Novozymes, Bagsvaerd, Denmark) was used in a total hydrolysis 
reaction mixture of $50 \mathrm{~kg}$. Enzymatic hydrolysis was performed at $\mathrm{pH} 5.0$ and $50{ }^{\circ} \mathrm{C}$, and using a stirring speed of $100 \mathrm{rpm}$. The duration of the hydrolysis was $40 \mathrm{~h}$. After hydrolysis, the $\mathrm{pH}$ of the hydrolysate was adjusted to around 3 with sulfuric acid. The hydrolysate was then sterile-filtered and stored in a cold room. High-performance anion-exchange chromatography (HPAEC, Dionex ICS-3000 system, Sunnyvale, CA, USA) was used to determine the concentrations of monosaccharide sugars. The HPAEC system was equipped with a pulsed amperometric detector, a $3 \mathrm{~mm} \times 30 \mathrm{~mm}$ guard column, and a $3 \mathrm{~mm} \times 150 \mathrm{~mm}$ separation column (CarboPac PA20, Dionex). The sugar concentrations were $130.5 \mathrm{~g} / \mathrm{L}$ glucose, $1.2 \mathrm{~g} / \mathrm{L}$ xylose, and $0.4 \mathrm{~g} / \mathrm{L}$ mannose. No other kinds of sugars were detected by using the HPAEC analysis. Before being used as culture medium, the fiber sludge hydrolysate was autoclaved at $105^{\circ} \mathrm{C}$ for $1 \mathrm{~h}$ and then filtrated. The CTMP of birch was kindly offered by Dr. Mattias Andersson from Mid Sweden University (Örnsköldsvik, Sweden).

\subsection{Culture Media}

The seed culture medium contained $25 \mathrm{~g} / \mathrm{L}$ glucose, $5 \mathrm{~g} / \mathrm{L}$ peptone, and $3 \mathrm{~g} / \mathrm{L}$ yeast extract. The $\mathrm{pH}$ was 5.0.

In a series of experiments on the feasibility of using fiber sludge hydrolysate as a carbon source for BNC production in shake-flask cultures, the fermentation culture medium contained $40 \mathrm{~g} / \mathrm{L}$ glucose (which was either spectral grade glucose in reference fermentations or diluted fiber sludge hydrolysate), $10 \mathrm{~g} / \mathrm{L}$ peptone, $6 \mathrm{~g} / \mathrm{L}$ yeast extract, and $100 \mathrm{mM}$ sodium acetate buffer. The final $\mathrm{pH}$ was adjusted to 5.0 using a $4 \mathrm{M}$ aqueous solution of $\mathrm{NaOH}$. The volume of medium in each 250-mL shake-flask was $100 \mathrm{~mL}$.

In a series of experiments on optimization of cultivation conditions in STRs, the fermentation culture medium contained $40 \mathrm{~g} / \mathrm{L}$ glucose (from diluted fiber sludge hydrolysate), $10 \mathrm{~g} / \mathrm{L}$ peptone, and $6 \mathrm{~g} / \mathrm{L}$ yeast extract. The final $\mathrm{pH}$ was adjusted to 5.0 using the $4 \mathrm{M}$ aqueous solution of $\mathrm{NaOH}$. The volume of medium in each 400-mL STR was $300 \mathrm{~mL}$.

\subsection{Preparation of Seed Culture and Inoculation}

One tube of glycerol stock of the bacterial strain was transferred to $100 \mathrm{~mL}$ seed culture medium, which was cultivated statically in an incubator at $30{ }^{\circ} \mathrm{C}$ for 4 days. Then, the inoculum was homogenized by using glass beads. The resulting homogenized seed culture was used for the inoculation $(5 \%(v / v))$ of both shake-flask and STR cultures.

\subsection{Study of Feasibility of Using Fiber Sludge Hydrolysate as a Carbon Source}

Shake-flask cultivations were performed in an orbital shaker (Ecotron, Infors HT, Bottmingen Switzerland) set at $110 \mathrm{rpm}$ and $30^{\circ} \mathrm{C}$. A sample of $1 \mathrm{~mL}$ culture fluid was taken every two days for determining $\mathrm{pH}$ and residual glucose concentration. After four and eight days of cultivation, $0.5 \mathrm{~mL}$ $10 \mathrm{M}$ ( $\mathrm{pH}$ 5.0) sodium acetate buffer was added to each shake-flask. BNC was harvested after 12 days. Triplicate cultivations were performed and mean values are reported.

\subsection{Study on Optimization of Cultivation Conditions in STRs}

The effect of stirring speed (50, 150, and $250 \mathrm{rpm}$ ) was studied at $30^{\circ} \mathrm{C}$ and with an airflow of 1.0 vvm using a multibioreactor system (Multifors, Infors HT, Bottmingen, Switzerland) equipped with $400 \mathrm{~mL}$ vessels. The $\mathrm{pH}$ of the medium was not adjusted during the cultivation. The $\mathrm{pH}$ and $\mathrm{DO}$ of each culture were recorded every two days. The effect of airflow ( 0.5 and $1.5 \mathrm{vvm})$ was studied at $30{ }^{\circ} \mathrm{C}$ and a stirring speed of $250 \mathrm{rpm}$. The effect of adjustment of $\mathrm{pH}$ was studied at $30^{\circ} \mathrm{C}$ using a stirring speed of $250 \mathrm{rpm}$ and an airflow of $1.0 \mathrm{vvm}$. The $\mathrm{pH}$ of the medium in one bioreactor was not adjusted during the cultivation, while the $\mathrm{pH}$ of the medium of another bioreactor was adjusted to around 5 every two days using the $4 \mathrm{M}$ aqueous solution of $\mathrm{NaOH}$.

During cultivations, a sample of $1 \mathrm{~mL}$ culture broth was taken every two days for determining the concentration of residual glucose. After 12 days, crude BNC was harvested by centrifugation at 
$14,000 \times g$. In order to assure that the purity of the BNC was sufficient for determining the average viscometric degree of polymerization $\left(D P_{\mathrm{v}}\right)$, crude $\mathrm{BNC}$ was washed at least three times at $80{ }^{\circ} \mathrm{C}$ (each time for four hours) using a $0.1 \mathrm{M}$ aqueous solution of $\mathrm{NaOH}$, until the $\mathrm{BNC}$ became white. After that, it was washed at least five times with deionized water at $80{ }^{\circ} \mathrm{C}$ for four hours. The washing with $\mathrm{NaOH}$ solution was performed a larger number of times and for longer periods than which are commonly used (washing one time for no more than one hour) [19,31]. The purified BNC was freeze-dried and weighed. After washing and weighing, the $D P_{\mathrm{v}}$ was analyzed.

\subsection{Analysis of Sugar Concentration}

The glucose concentration was measured by using a glucometer (Accu-Chek Aviva, Roche Diabetes Care, Mannheim, Germany). A standard curve was established using a series of glucose solutions with known concentrations. Before measurements, broth samples were diluted 25 times with glucometer buffer (prepared as indicated by the manufacturer). The glucose concentration of each broth sample was measured three times, and the concentration values were recalculated using the standard curve. The concentrations of other monosaccharides were not measured, as they were negligible compared to glucose.

\subsection{Measurement of $D P_{v}$ of $B N C$}

The $D P_{\mathrm{v}}$ of the BNC was measured three times with a viscometer (Schott Gerate, Typ 52503/0c, $\mathrm{K}=0.002879$, Mainz, Germany) according to a method suggested by Evans and Wallis [32]. This method was modified from the American National Standard of ASTM D4243-99 [33], and is better for measuring the high $D P_{\mathrm{v}}$ of BNC according to Evans and Wallis [32].

\subsection{Effects of BNC Addition on the Mechanical Properties of Birch CTMP Paper Sheets}

CTMP and CTMP/BNC paper sheets were manufactured by MoRe Research AB (Örnsköldsvik, Sweden), who also determined the mechanical properties. Purified BNC from the optimal cultivation conditions was disintegrated using a blender (YD-2318S, Clas Ohlson, Insjön, Sweden) at a concentration of around $2 \mathrm{~g} / \mathrm{L}$ for $6 \mathrm{~min}$. The exact dry mass of the BNC in the homogenate was measured. Laboratory wet disintegration of the CTMP of birch was performed according to ISO 5263-3:2004 [34]. The homogenate of BNC was mixed with the disintegrated CTMP to achieve concentrations of $5 \%$ and $10 \%(w / w)$ BNC in the CTMP/BNC mixtures. The mixture was mixed using an impeller at $1500 \mathrm{rpm}$ for $5 \mathrm{~min}$. Paper sheets were made from the mixture according to the Rapid-Köthen method (ISO 5269-2:2004) [35]. A paper filter with a pore size of 7-10 $\mu \mathrm{m}$ (242001, Munktell, Falun, Sweden) and a polyester filter with a pore size of around $71 \mu \mathrm{m}$ (PES71N, Momodur, Eczacıbaşı Anasayfa, Istanbul, Turkey) were put on the sheet-forming screen of the Rapid-Köthen apparatus to enhance the retention of BNC. All tests were made in a climate room, as specified in ISO 187:1990 [36]. The grammage of the paper sheets was measured according to ISO 536:2012 [37]. The tensile strength of the paper sheets was determined according to ISO 1924-3:2005 [38]. The tear resistance was studied based on ISO 1974:2012 [39].

\subsection{Scanning Electron Microscopy}

The paper samples were placed onto a carbon tape-mounted aluminum stub, and sputtered-coated with $5 \mathrm{~nm} \mathrm{Au/Pd}$ (Quorum Q150T ES, Lewes, United Kingdom). The morphology of the samples was examined by using field-emission scanning electron microscopy (FESEM) (Merlin, Carl Zeiss AG, Jena, Germany) equipped with an in-lens secondary electron detector at accelerating voltage of $4 \mathrm{kV}$ and a probe current of $120 \mathrm{pA}$. 


\section{Results and Discussion}

\subsection{Feasibility of Using Fiber Sludge Hydrolysate as a Carbon Source in Shake-Flask Cultures}

In the first series of experiments, the fiber sludge hydrolysate was compared with a reference medium based on synthetic glucose with regard to fermentability (measured as glucose consumption) and the productivity, yield, and $D P_{\mathrm{v}}$ of BNC. As acetate buffer could increase production of BNC [40], the media were buffered with sodium acetate. The $\mathrm{pH}$ adjustments with sodium acetate were carried out on days 4 and 8 (Figure 1A). However, there was a lag phase of four days for both media, and even at the end of the cultivation much of the glucose was still left (Figure 1B). The glucose consumption in the hydrolysate was faster than in the reference medium (Figure 1B, Table 1), but still no more than $0.77[\mathrm{~g} /(\mathrm{L} \times \mathrm{d})]$. As the overall glucose consumption (Figure 1B) and the BNC yield on initial glucose (0.036-0.055 g/g, Table 1) were rather modest, the following experimental series were carried out without acetate buffer and mostly without $\mathrm{pH}$ adjustment.
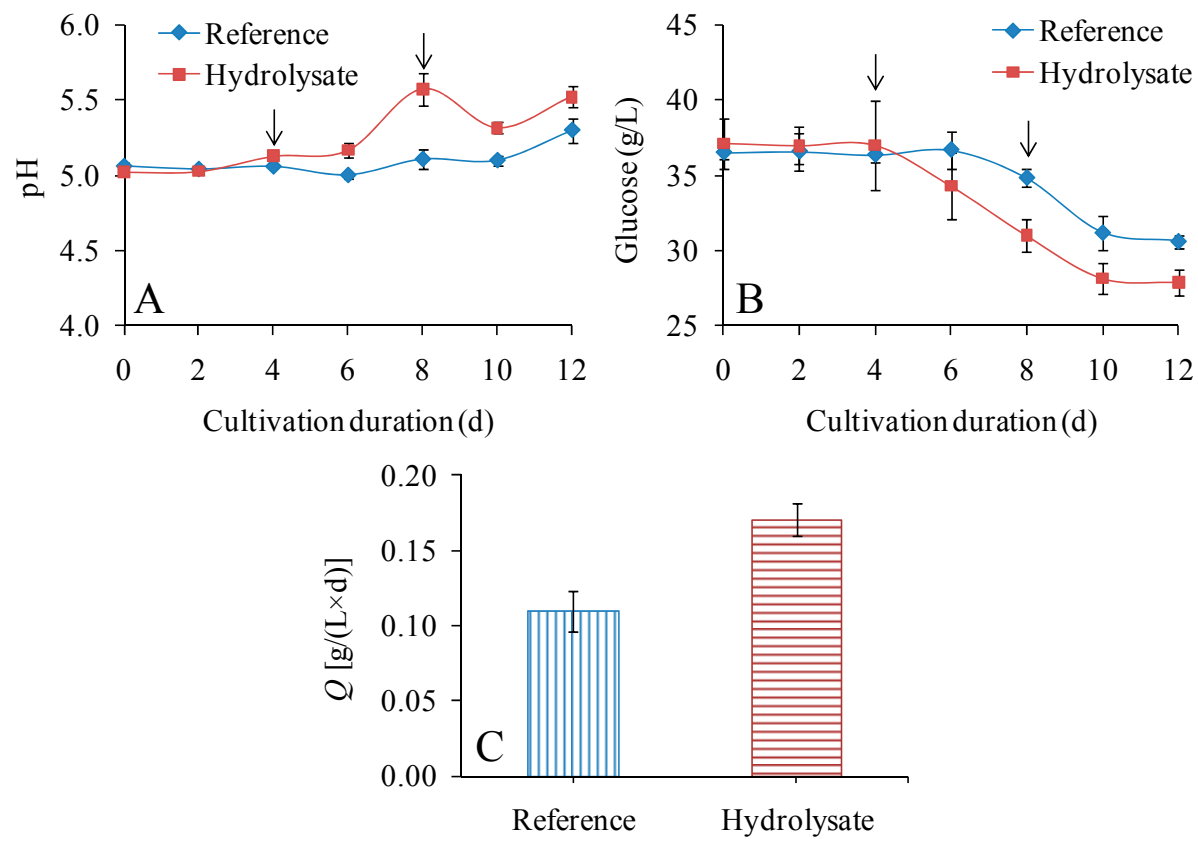

Carbon source

Figure 1. Graphs showing $\mathrm{pH}(\mathbf{A})$, residual glucose concentration (B), and volumetric productivity (C) in reference medium and hydrolysate-based medium in shake-flask experiments. The arrows show time points for addition of acetate buffer during the cultivations. The volume of the culture medium was $100 \mathrm{~mL}$ (250-mL flasks), the shaking speed was $110 \mathrm{rpm}$, and the cultivation temperature was $30^{\circ} \mathrm{C}$.

Table 1. Glucose consumption, bacterial nanocellulose (BNC) productivity, BNC yield, and viscometric degree of polymerization $\left(D P_{\mathrm{v}}\right)$ in shake-flask experiments ${ }^{\mathrm{a}}$.

\begin{tabular}{cccccc}
\hline Medium & $\begin{array}{c}\text { Glucose Consumption } \\
\text { Rate }[\mathbf{g} /(\mathbf{L} \times \mathbf{d})]\end{array}$ & $\boldsymbol{Q}[\mathbf{g} / \mathbf{L} \times \mathbf{d})]$ & $\boldsymbol{Y}_{\text {P/initial G }}(\mathbf{g} / \mathbf{g})$ & $\boldsymbol{Y}_{\text {P/consumed G }}(\mathbf{g} / \mathbf{g})$ & $\mathbf{D P} \mathbf{v}$ \\
\hline Reference & $0.47 \pm 0.04$ & $0.110 \pm 0.013$ & $0.036 \pm 0.003$ & $0.235 \pm 0.010$ & $6760 \pm 110$ \\
Hydrolysate & $0.77 \pm 0.07$ & $0.171 \pm 0.011$ & $0.055 \pm 0.001$ & $0.223 \pm 0.010$ & $6050 \pm 80$ \\
\hline \multicolumn{6}{c}{ a The BNC was purified by washing with alkali and water. }
\end{tabular}

The value for volumetric productivity of BNC (Table 1) was 55\% higher for the hydrolysate medium than for the reference medium. Similarly, the value for BNC yield on initial sugar (Table 1) was $53 \%$ higher for the hydrolysate medium than for the reference medium. The yields on consumed glucose were, however, quite similar: $0.235 \mathrm{~g} / \mathrm{g}$ for the reference medium and $0.223 \mathrm{~g} / \mathrm{g}$ for the 
hydrolysate (Table 1). It is possible that denatured cellulase and other trace components in the hydrolysate promoted bacterial metabolism and growth. As a result, glucose consumption and especially BNC production might have been enhanced. The $D P_{\mathrm{v}}$ was slightly higher for the BNC from the reference medium (6760) than for the BNC from the hydrolysate medium (6050) (Table 1).

Compared with many other studies in the field, the volumetric BNC productivity, the yield of $\mathrm{BNC}$, and the $D P_{\mathrm{v}}$ were generally good, despite using submerged cultivations, a medium based on industrial residues, and a very extensive washing scheme. Cavka et al. [11] investigated the production of BNC from enzymatic hydrolysate of waste fiber sludge by K. xylinus ATCC 23770 after static cultivation. Using hydrolysates of sulfite fiber sludge as carbon source, they found that volumetric productivity of BNC was $5 \%$ lower than for a medium based on synthetic glucose [11], while in the current study it was instead $>50 \%$ higher. The advantageous effect on BNC productivity observed in our study could possibly be related to better mixing in submerged cultivation and to the special characteristics of strain DHU-ZGD-1186. Using static cultivation and $200 \mathrm{mM}$ acetate buffer in the medium, Kuo et al. [40] reached a BNC yield on consumed glucose of $0.23 \mathrm{~g} / \mathrm{g}$, which can be compared to $0.22-0.24 \mathrm{~g} / \mathrm{g}$ in our study. In the study of Shibazaki et al. [41], K. xylinus ATCC 23769 was cultivated for 5-7 days, and then the BNC was harvested and purified by boiling in a $1 \%$ solution of $\mathrm{NaOH}$. Measuring DP with a similar method [42] as we used in our study, they reported a $D P_{\mathrm{v}}$ of 2000 for BNC and 2280 for cotton linter [41]. This can be compared with the $D P_{\mathrm{v}}$ values of the BNC in our study, which were always $>6000$. The higher $D P_{\mathrm{v}}$ of the BNC in our study could possibly be attributed to the characteristics of strain DHU-ZGD-1186, to the longer duration of the cultivation (12 days), and to the lower $\mathrm{NaOH}$ concentration $(4 \mathrm{~g} / \mathrm{L})$ in the washing.

\subsection{Effect of Stirring Speed on the Production of BNC in STRs}

As the results achieved in shake-flasks indicated that the hydrolysate was about as good as or even better than the glucose-based reference medium, the next step was moving from shake-flasks to STRs for improving submerged cultivation conditions for fiber sludge hydrolysate. The stirring speed, the aeration, and the potential benefits of $\mathrm{pH}$ adjustment were studied.

In the first series of bioreactor experiments, stirring speeds in the range 50-250 rpm were compared (Figure 2, Table 2). As the medium was not buffered, the $\mathrm{pH}$ dropped from 5 to about 3 during the cultivation (Figure 2A). The change in $\mathrm{pH}$ was the same for all three stirring speeds tested, and there was no sign of a four-day lag phase as in the shake-flask experiment (Figure 2A). Instead, the $\mathrm{pH}$ dropped fast from 5 to about 3.5 during the first four days, and after that it decreased slowly to about 3 during the next eight days (Figure 2A). Similarly, the DO dropped rapidly during the first four days and remained at low levels until the end of the cultivation (Figure 2B).

Table 2. Influence of stirring speed, airflow and $\mathrm{pH}$ adjustment of the fiber sludge hydrolysate medium on glucose consumption, BNC productivity, BNC yield, and $D P_{\mathrm{v}}$. The experiments with different variables were conducted separately ${ }^{\mathrm{a}}$.

\begin{tabular}{|c|c|c|c|c|c|c|}
\hline Variable & Conditions & $\begin{array}{c}\text { Glucose } \\
\text { Consumption Rate } \\
{[g /(L \times d)]}\end{array}$ & $Q[\mathrm{~g} /(\mathrm{L} \times \mathrm{d})]$ & $Y_{P / \text { initial G }}(g / g)$ & $\begin{array}{c}Y_{\mathrm{P} / \text { consumed G }} \\
(\mathrm{g} / \mathrm{g})\end{array}$ & $D P_{\mathrm{v}}$ \\
\hline \multirow{2}{*}{$\begin{array}{l}\text { Stirring speed } \\
\quad(1.0 \mathrm{vvm})\end{array}$} & $50 \mathrm{rpm}$ & $2.96 \pm 0.07$ & $0.202 \pm 0.010$ & $0.056 \pm 0.002$ & $0.068 \pm 0.006$ & $6390 \pm 90$ \\
\hline & $250 \mathrm{rpm}$ & $3.21 \pm 0.04$ & $0.262 \pm 0.013$ & $0.072 \pm 0.002$ & $0.082 \pm 0.003$ & $6210 \pm 30$ \\
\hline \multirow{2}{*}{ Airflow (250 rpm) } & $0.5 \mathrm{vvm}$ & $2.61 \pm 0.11$ & $0.255 \pm 0.013$ & $0.073 \pm 0.004$ & $0.098 \pm 0.007$ & $6650 \pm 70$ \\
\hline & $1.5 \mathrm{vvm}$ & $2.58 \pm 0.04$ & $0.266 \pm 0.013$ & $0.079 \pm 0.004$ & $0.103 \pm 0.007$ & $6200 \pm 60$ \\
\hline
\end{tabular}

a The BNC was purified by washing with alkali and water. 

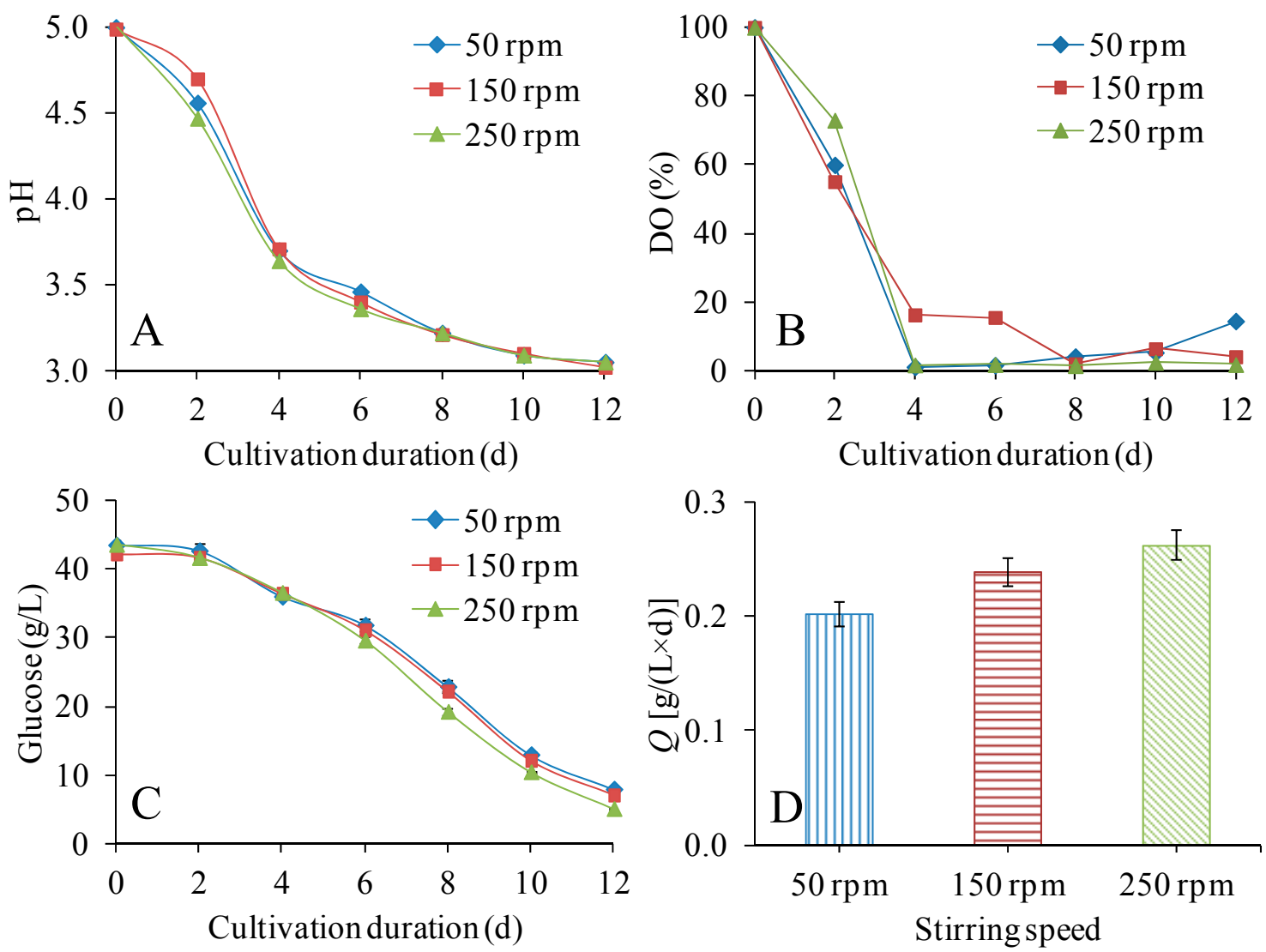

Figure 2. Effects of stirring speed on $\mathrm{pH}(\mathbf{A})$, dissolved oxygen (DO) (B), residual glucose concentration (C), and volumetric productivity (D). The volume of culture medium was $300 \mathrm{~mL}$ (in $400 \mathrm{~mL}$ stirred-tank reactors (STRs)), and the cultivation temperature was $30^{\circ} \mathrm{C}$.

Even if glucose consumption was slow for the first two days, the data (Figure 2C) indicated a clear improvement compared to the shake-flask experiments (Figure 1B). That could be attributed to better mixing of the medium and better air supply. The improvement compared to the shake-flask cultures is further highlighted by data in Table 2, which shows glucose consumption rates of about $3 \mathrm{~g} /(\mathrm{L} \times \mathrm{d})$ and volumetric $\mathrm{BNC}$ productivities ranging from 0.20 to $0.26 \mathrm{~g} /(\mathrm{L} \times \mathrm{d})$. Whereas no clear difference in glucose consumption for 50 and $150 \mathrm{rpm}$ was detected (Figure 2, Table 2), the volumetric BNC productivity and the BNC yield on initial glucose steadily increased with increasing stirring speed (Table 2). The BNC yield of consumed glucose was in the range $0.068-0.082 \mathrm{~g} / \mathrm{g}$, significantly lower than in the shake-flask experiments and independently of the medium with which the comparison was made (Table 1). The decrease in yield on consumed glucose may be related to the absence of acetate buffer in the STRs as compared with the shake-flasks. Kuo et al. [40] found that the yield of BNC on consumed glucose in medium without acetate buffer was just $0.06 \mathrm{~g} / \mathrm{g}$, much lower than the $0.23 \mathrm{~g} / \mathrm{g}$ achieved in medium with $200 \mathrm{mM}$ acetate buffer. They also found higher levels of the by-product gluconate $(15.02 \mathrm{~g} / \mathrm{L})$ in the medium without acetate buffer than in the medium with acetate buffer $(11.46 \mathrm{~g} / \mathrm{L})$ [40], which would have contributed to lower BNC yield on consumed glucose.

The $D P_{\mathrm{v}}$ values were in the narrow range 6210-6480, with the highest stirring speed giving the lowest $D P_{\mathrm{v}}$ (Table 2). Comparing the same medium, the $D P_{\mathrm{v}}$ values in the bioreactor experiment (Table 2) were higher than the $D P_{\mathrm{v}}$ value in the shake-flask experiment (Table 1). The difference between $6390(50 \mathrm{rpm})$ and $6480(150 \mathrm{rpm})$ was not significant $(p>0.05)$, but the decrease from 6480 to 6210 was significant $(p \leq 0.01)$. Watanabe et al. [31] reported that agitation could result in decreased $D P_{\mathrm{v}}$ of BNC. They produced BNC in a 1 L STR with stirring speed high enough to maintain the DO 
concentration above $1.0 \mathrm{ppm}$. The weight-average degree of polymerization of the BNC from the STR cultivation was found to be 10,900 , lower than that of 14,400 from static cultivation [31].

\subsection{Effect of Airflow on the Production of BNC in STRs}

In the experimental series with different stirring speeds, the air flow was set to $1 \mathrm{vvm}$; in the second set of experiments in the bioreactor, this setting was compared to lower $(0.5 \mathrm{vvm})$ and higher (1.5 vvm) airflow, using $250 \mathrm{rpm}$ as the stirring speed (Figure 3, Table 2). As seen in Figure 3A,C, the $\mathrm{pH}$ change and the glucose consumption were similar in bioreactors with different airflow. The glucose consumption rate was about $2.6 \mathrm{~g} /(\mathrm{L} \times \mathrm{d})$ (Table 2$)$ with no significant $(p>0.05)$ differences. As seen in Figure 3B, the DO was higher when the airflow was $1.5 \mathrm{vvm}$, especially at the beginning and at the end of the cultivation.
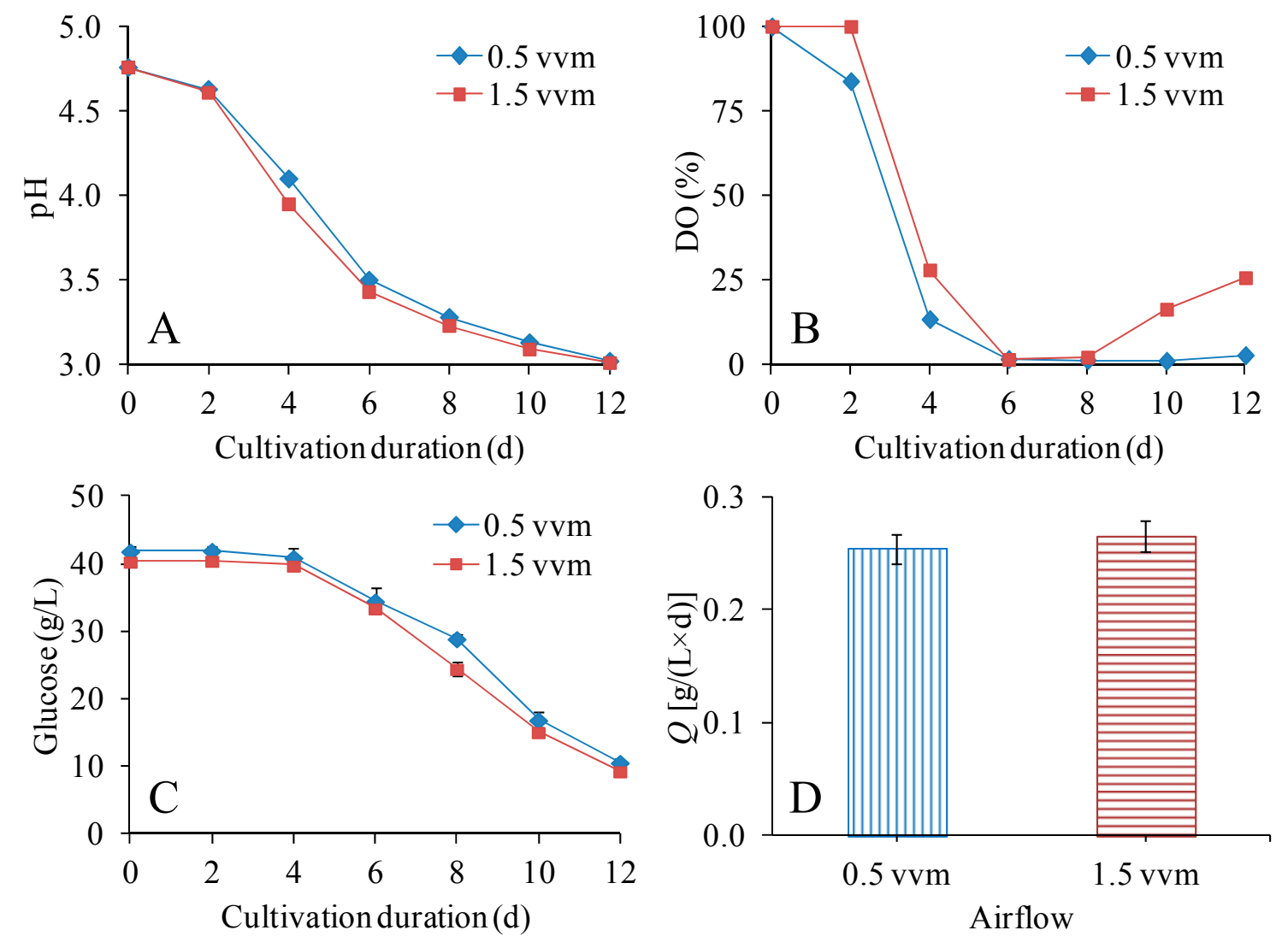

Figure 3. Effects of airflow on $\mathrm{pH}(\mathbf{A})$, DO (B), residual glucose concentration (C), and volumetric productivity (D). The volume of the culture medium was $300 \mathrm{~mL}$ (400-mL STR) and the cultivation temperature was $30^{\circ} \mathrm{C}$.

The values for volumetric productivity of BNC, BNC yield on initial glucose, and BNC yield on consumed glucose were higher for cultivation with $1.5 \mathrm{vvm}$ than for cultivation with $0.5 \mathrm{vvm}$, but the differences were not significant $(p>0.05)$. Although that effect could be seen in our experiments (Table 2), it has been reported that increasing the airflow could increase the productivity of BNC, due to the decreased partial pressure of $\mathrm{CO}_{2}$ in the gaseous phase [21].

With an airflow of 0.5 and $1.5 \mathrm{vvm}$, the $D P_{\mathrm{v}}$ of the BNC was 6650 and 6200, respectively (Table 2). It is speculated that the high airflow of $1.5 \mathrm{vvm}$ perhaps disturbed the biosynthesis of BNC, especially before the BNC turned to gel. The $D P_{\mathrm{v}}$ with $1.5 \mathrm{vvm}$ was similar to the $D P_{\mathrm{v}}$ with $1.0 \mathrm{vvm}(6210)$ (Table 2). It is noteworthy that while both high stirring speed and high air flow tended to result in lower $D P_{\mathrm{v}}$, a high $D P_{\mathrm{v}}(6650)$ could still be achieved by combining high stirring speed (250 rpm) with 
low air flow $(0.5 \mathrm{vvm})$ without any significant decreases in volumetric productivity of BNC, BNC yield on initial glucose, or BNC yield on consumed glucose (Table 2).

\subsection{Effect of $\mathrm{pH}$ Adjustment on the Production of BNC in STRs}

Cultivation in acetate-buffered medium in shake-flasks resulted in relatively low sugar utilization, and most of the experiments in STRs were performed without $\mathrm{pH}$ control; however, one experimental series covered $\mathrm{pH}$ adjustment in STRs using a solution of sodium hydroxide (Figure 4, Table 2). Figure $4 \mathrm{~A}$ shows the $\mathrm{pH}$ during the cultivations, which were performed using a stirring speed of $250 \mathrm{rpm}$ and an air flow of $1.0 \mathrm{vvm}$. Without $\mathrm{pH}$ adjustment, the $\mathrm{pH}$ decreased to about 3.0 after cultivation for 12 days. With $\mathrm{pH}$ adjustment, the $\mathrm{pH}$ was kept within the range 4.0-5.0 (Figure 4A).
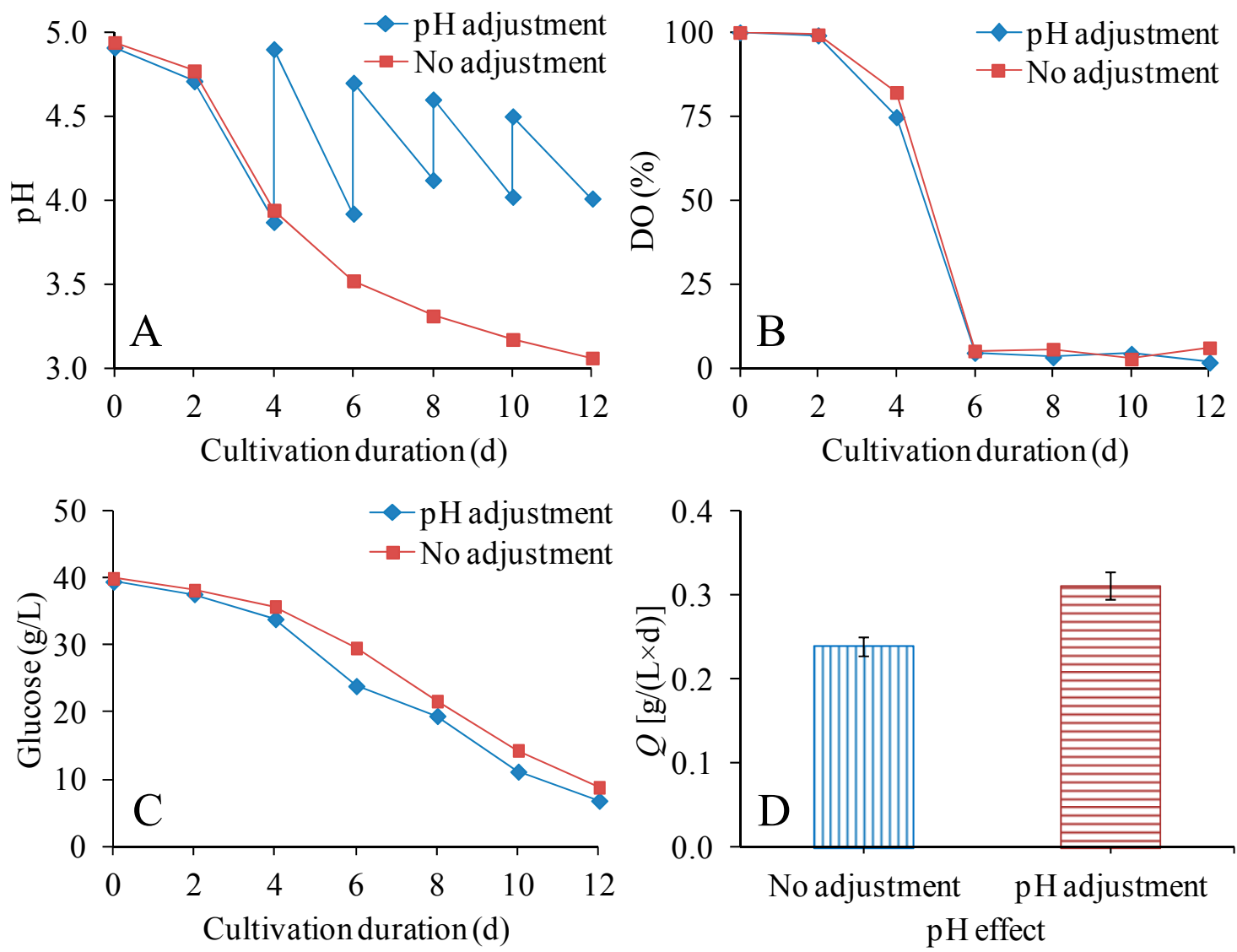

Figure 4. Effects of $\mathrm{pH}$ adjustment on $\mathrm{pH}(\mathbf{A}), \mathrm{DO}(\mathbf{B})$, residual glucose concentration (C), and volumetric productivity (D). The volume of culture medium was $300 \mathrm{~mL}(400-\mathrm{mL} \mathrm{STR})$ and the cultivation temperature was $30^{\circ} \mathrm{C}$.

The effects of $\mathrm{pH}$ adjustment on DO (Figure 4B) and glucose consumption (Figure 4C) were rather small. However, the $\mathrm{pH}$ adjustment had a clear positive effect on volumetric productivity of BNC, BNC yield on initial glucose, and BNC yield on consumed glucose (Table 2). This result agrees with reports that the $\mathrm{pH}$ of the medium strongly affects $\mathrm{BNC}$ production and that the optimal $\mathrm{pH}$ for $\mathrm{BNC}$ production is in the range of 4.0-6.0, as this is a favorable $\mathrm{pH}$ range for the bacteria $[20,43]$. An adjustment of $\mathrm{pH}$ resulted in a decrease of the $D P_{\mathrm{v}}$ of BNC from 6310 to 6080 (Table 2). This could possibly be related to the function of the cellulase produced by K. xylinus. The $\mathrm{pH}$ range of 4.0-5.0 in the medium with $\mathrm{pH}$ adjustment could lead to higher cellulase activity and result in lower $D P_{\mathrm{v}}$. Previously Tahara et al. [44] studied the $\mathrm{pH}$ effect on BNC productivity and $D P_{\mathrm{v}}$. They found that in a medium with a constant $\mathrm{pH}$ of 5 , both the BNC productivity and the cellulase activity were higher 
than in a medium with $\mathrm{pH} 4$. Due to the higher cellulase activity, the $D P_{\mathrm{v}}$ decreased in the medium with a $\mathrm{pH}$ of 5 [44].

\subsection{Effects of BNC Addition on the Mechanical Properties of Birch CTMP Paper Sheets}

A series of CTMP paper sheets containing no BNC, 5\% BNC, and 10\% BNC was prepared to test the effects of inclusion of BNC on the mechanical properties of the paper sheets, which are shown in Table 3. The addition of $5 \%$ or $10 \%$ BNC did not have any clear effect on grammage or thickness, but a slight increase in density could be discerned (Table 3). The addition of BNC did, however, result in increases of tensile index, tensile stiffness index, tensile energy absorption index, strain at break, E-modulus, and tear index (Table 3). For example, the increase in tensile index amounted to $16 \%$ for $5 \%$ BNC and $49 \%$ for $10 \%$ BNC. The increase in tear index amounted to $66 \%$ for $5 \%$ BNC and $140 \%$ for $10 \%$ BNC. In most cases, there were significant differences not only between BNC-less and BNC-containing paper sheets $(p \leq 0.05)$, but also between paper sheets containing $5 \%$ and $10 \%$ BNC $(p \leq 0.05)$. An exception was the strain at break, for which there was no significant difference between sheets with $0 \%, 5 \%$ or $10 \%$ BNC ( $p>0.05)$ (Table 3$)$.

Table 3. Mechanical properties of paper sheets made from chemithermomechanical pulp (CTMP) with $\mathrm{BNC}$ as an additive.

\begin{tabular}{|c|c|c|c|}
\hline Fraction of BNC (w/w \%) & 0 & 5 & 10 \\
\hline Grammage, paper $\left(\mathrm{g} / \mathrm{m}^{2}\right)$ & $57.1 \pm 2.6$ & $59.0 \pm 1.4$ & $58.7 \pm 3.2$ \\
\hline Thickness (mm) & $0.16 \pm 0.01$ & $0.16 \pm 0.01$ & $0.15 \pm 0.01$ \\
\hline Density $\left(\mathrm{kg} / \mathrm{m}^{3}\right)$ & $354 \pm 20$ & $374 \pm 7$ & $389 \pm 8$ \\
\hline Tensile Index $(\mathrm{kNm} / \mathrm{kg})^{a}$ & $16.6 \pm 1.7$ & $19.3 \pm 1.5$ & $24.7 \pm 2.5$ \\
\hline Tensile stiffness index $(\mathrm{MNm} / \mathrm{kg})^{b}$ & $3.45 \pm 0.30$ & $4.05 \pm 0.11$ & $4.97 \pm 0.43$ \\
\hline Tensile energy absorption index $(\mathrm{J} / \mathrm{kg})^{\mathrm{c}}$ & $56.7 \pm 9.2$ & $69.3 \pm 10.9$ & $87.7 \pm 15.7$ \\
\hline Strain at break (\%) & $0.601 \pm 0.032$ & $0.624 \pm 0.061$ & $0.626 \pm 0.075$ \\
\hline E-modulus (GPa) & $1.22 \pm 0.08$ & $1.51 \pm 0.05$ & $1.89 \pm 0.20$ \\
\hline Tear Index $\left(\mathrm{mNm}^{2} / \mathrm{g}\right)^{\mathrm{d}}$ & $1.35 \pm 0.28$ & $2.24 \pm 0.07$ & $3.20 \pm 0.20$ \\
\hline
\end{tabular}

\footnotetext{
a Tensile strength determined as the maximum tensile force per unit width the sheet will withstand before breaking, and tensile index determined as tensile strength divided by grammage. ${ }^{b}$ The tensile stiffness determined as the maximum slope of the curve obtained when tensile force per unit width is plotted versus strain, and tensile stiffness index determined as tensile stiffness divided by grammage. Elastic modulus (E-modulus) determined as tensile stiffness divided by thickness. ${ }^{c}$ Tensile energy absorption determined as the amount of energy per unit surface area (test length $\times$ width) of a test piece when it is strained to the maximum tensile force. Tensile energy absorption index determined as tensile energy absorption divided by grammage. ${ }^{d}$ Tearing resistance determined as the average force per sheet required to continue the tearing started by an initial cut in the test piece. Tearing index determined as tearing resistance divided by grammage.
}

Our results show that introduction of BNC could significantly enhance the mechanical properties of CTMP-based paper sheets. It has been reported that BNC could enhance the tensile properties and tear index of paper made of cotton lint pulp, softwood pulp, and kraft pulp of birch and pine [23,24,45]. Surma-Ślusarska et al. found that, with 15\% disintegrated BNC in paper sheets of kraft pulp of birch, the tear index was enhanced by $33 \%$ [45]. This can be compared with our results showing an increase in tear index by $66 \%$ for paper sheets with $5 \%$ BNC and an increase with $140 \%$ for paper sheets with $10 \%$ BNC. The higher increase observed in our study can be explained by the use of different types of pulp and different paper qualities, but possibly also by the use of BNC of different qualities, such as different DP.

To explain the mechanism of the enhancement in more detail, SEM images of the paper sheets were taken, as shown in Figure 5. Figure 5(B1) and 5(C1) (magnification 750 $\times$ ) show that the BNC covered the gap between CTMP fibers. Figure 5(B2) and 5(C2) (magnification 5000 $\times$ ) show that the BNC cross-linked different CTMP fibers, and that it also covered the surface of the CTMP fibers, which is also shown in Figure 5(B3) and 5(C3) (magnification 50,000×). Figure 5(B3) and 5(C3) show particularly well how single BNC fibers were in contact with the pulp fibers. Since the BNC attached 
strongly to the surface of the CTMP fibers, the CTMP fibers became difficult to separate from each other, resulting in a great improvement of the tear index.
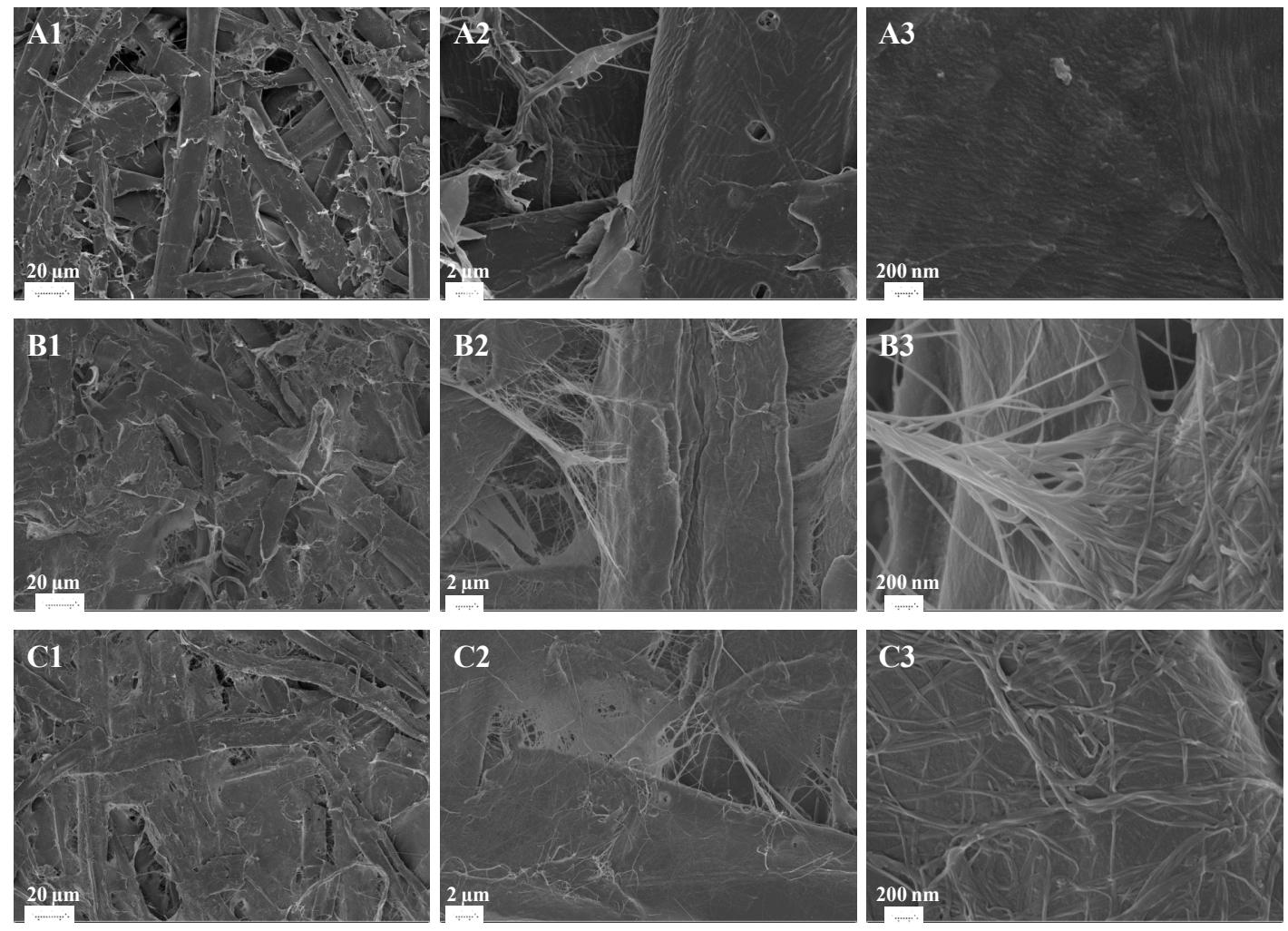

Figure 5. SEM images of paper sheets of birch CTMP, and CTMP and BNC mixtures. Fraction of BNC: (A1-A3) 0 w/w \%; (B1-B3) $5 w / w \%$; (C1-C3) $10 w / w \%$. Amplifications: (A1-C1) 750×; (A2-C2) $5000 \times ;($ A3-C3) 50,000×.

\section{Conclusions}

This work shows how an enzymic hydrolysate of waste fiber sludge could be converted to high value-added BNC and be used to enhance the properties of CTMP paper sheets, thus taking care of a waste stream and enhancing a product, both of which come from the forest industry. The data indicate that the fiber sludge hydrolysate was even better than a reference medium based on a synthetic glucose solution. The investigation also shows important connections between cultivation conditions and the yield and DP of the BNC; for instance, regarding submerged cultivation in shake-flasks vs. cultivation in STRs, stirring speed, aeration, and $\mathrm{pH}$ adjustment. Initial studies of the effects of BNC on papermaking using CTMP were also performed, and it was shown that the BNC could significantly enhance the mechanical properties of the paper and, especially, the tear resistance, as BNC could cross-link the CTMP fibers and cover their surface. More investigations are needed to clarify why fiber sludge hydrolysates can be superior to synthetic glucose for BNC production, to decrease the enzyme cost and other costs, to up-scale BNC production in STRs, and to further explore and optimize the use of BNC to reinforce materials based on plant cellulose.

Acknowledgments: We would like to thank Mattias Andersson (Mid Sweden University) for providing CTMP of birch. Zhao Wang (Umeå University) is thanked for the HPAEC analysis of the sulfite fiber sludge hydrolysate. Ove Andersson (Umeå University) is acknowledged for help with the DP analysis. We appreciate the services offered by MoRe Research (Örnsköldsvik, Sweden) and UCEM (Umeå Core Facility Electron Microscopy, KBC Chemical-Biological Centre, Umeå, Sweden). Financial support was provided by the National Natural Science Foundation of China (No. 51373031), the Science and Technology Commission of Shanghai Municipality (15520720800), the Swedish strategic research environment Bio4Energy (http:/ / www.bio4energy.se/), the Kempe 
Foundations (http:/ / www.kempe.com/), the State Key Laboratory for Modification of Chemical Fibers and Polymer Materials (Donghua University, LK1617), and the China Scholarship Council (201506630057).

Author Contributions: Genqiang Chen, Feng F. Hong and Leif J. Jönsson conceived and designed the experiments; Genqiang Chen, Guochao Wu, and Björn Alriksson performed the experiments; Genqiang Chen and Guochao $\mathrm{Wu}$ analyzed the data; Björn Alriksson and Leif J. Jönsson contributed reagents/materials/analysis tools; Genqiang Chen, Guochao Wu, Björn Alriksson, Wei Wang, Feng F. Hong and Leif J. Jönsson wrote the paper.

Conflicts of Interest: The authors declare no conflict of interest.

\section{References}

1. Gama, M.; Gatenholm, P.; Klemm, D. (Eds.) Bacterial Nanocellulose: A Sophisticated Multifunctional Material; CRC Press: Boca Raton, FL, USA, 2012.

2. Bielecki, S.; Krystynowicz, A.; Turkiewicz, M.; Kalinowska, H. Bacterial cellulose. In Biopolymers Online; Wiley-VCH Verlag GmbH \& Co. KGaA: Weinheim, Germany, 2005; pp. 5-7.

3. Mohite, B.V.; Patil, S.V. A novel biomaterial: Bacterial cellulose and its new era applications. Biotechnol. Appl. Biochem. 2014, 61, 101-110. [CrossRef] [PubMed]

4. Lee, K.-Y.; Buldum, G.; Mantalaris, A.; Bismarck, A. More than meets the eye in bacterial cellulose: Biosynthesis, bioprocessing, and applications in advanced fiber composites. Macromol. Biosci. 2014, 14, 10-32. [CrossRef] [PubMed]

5. Toyosaki, H.; Naritomi, T.; Seto, A.; Matsuoka, M.; Tsuchida, T.; Yoshinaga, F. Screening of bacterial cellulose-producing Acetobacter strains suitable for agitated culture. Biosci. Biotechnol. Biochem. 1995, 59, 1498-1502. [CrossRef]

6. White, D.G.; Brown, R.M., Jr. Prospects for the commercialization of the biosynthesis of microbial cellulose. In Cellulose and Wood-Chemistry and Technology; Wiley: Hoboken, NJ, USA, 1989; Volume 573, pp. 573-590.

7. Cacicedo, M.L.; Castro, M.C.; Servetas, I.; Bosnea, L.; Boura, K.; Tsafrakidou, P.; Dima, A.; Terpou, A.; Koutinas, A.; Castro, G.R. Progress in bacterial cellulose matrices for biotechnological applications. Bioresour. Technol. 2016, 213, 172-180. [CrossRef] [PubMed]

8. Hong, F.; Qiu, K. An alternative carbon source from konjac powder for enhancing production of bacterial cellulose in static cultures by a model strain Acetobacter aceti subsp. xylinus ATCC 23770. Carbohydr. Polym. 2008, 72, 545-549. [CrossRef]

9. Hong, F.; Zhu, Y.X.; Yang, G.; Yang, X.X. Wheat straw acid hydrolysate as a potential cost-effective feedstock for production of bacterial cellulose. J. Chem. Technol. Biotechnol. 2011, 86, 675-680. [CrossRef]

10. Chen, L.; Hong, F.; Yang, X.-X.; Han, S.-F. Biotransformation of wheat straw to bacterial cellulose and its mechanism. Bioresour. Technol. 2013, 135, 464-468. [CrossRef] [PubMed]

11. Cavka, A.; Guo, X.; Tang, S.-J.; Winestrand, S.; Jönsson, L.J.; Hong, F. Production of bacterial cellulose and enzyme from waste fiber sludge. Biotechnol. Biofuels 2013, 6, 25. [CrossRef] [PubMed]

12. Guo, X.; Cavka, A.; Jönsson, L.J.; Hong, F. Comparison of methods for detoxification of spruce hydrolysate for bacterial cellulose production. Microb. Cell Fact. 2013, 12, 93. [CrossRef] [PubMed]

13. Hong, F.; Guo, X.; Zhang, S.; Han, S.-F.; Yang, G.; Jönsson, L.J. Bacterial cellulose production from cotton-based waste textiles: Enzymatic saccharification enhanced by ionic liquid pretreatment. Bioresour. Technol. 2012, 104, 503-508. [CrossRef] [PubMed]

14. Guo, X.; Chen, L.; Tang, J.; Jönsson, L.J.; Hong, F.F. Production of bacterial nanocellulose and enzyme from [Amim]Cl-pretreated waste cotton fabrics: Effects of dyes on enzymatic saccharification and nanocellulose production. J. Chem. Technol. Biotechnol. 2016, 91, 1413-1421. [CrossRef]

15. Zhang, S.; Winestrand, S.; Guo, X.; Chen, L.; Hong, F.; Jönsson, L.J. Effects of aromatic compounds on the production of bacterial nanocellulose by Gluconacetobacter xylinus. Microb. Cell Fact. 2014, 13, 62. [CrossRef] [PubMed]

16. Zhang, S.; Winestrand, S.; Chen, L.; Li, D.; Jönsson, L.J.; Hong, F. Tolerance of the nanocellulose-producing bacterium Gluconacetobacter xylinus to lignocellulose-derived acids and aldehydes. J. Agric. Food Chem. 2014, 62, 9792-9799. [CrossRef] [PubMed]

17. Kouda, T.; Yano, H.; Yoshinaga, F. Effect of agitator configuration on bacterial cellulose productivity in aerated and agitated culture. J. Biosci. Bioeng. 1997, 83, 371-376. [CrossRef] 
18. Yoshinaga, F.; Tonouchi, N.; Watanabe, K. Research progress in production of bacterial cellulose by aeration and agitation culture and its application as a new industrial material. Biosci. Biotechnol. Biochem. 1997, 61, 219-224. [CrossRef]

19. Bae, S.; Shoda, M. Statistical optimization of culture conditions for bacterial cellulose production using Box-Behnken design. Biotechnol. Bioeng. 2005, 90, 20-28. [CrossRef] [PubMed]

20. Hwang, J.W.; Yang, Y.K.; Hwang, J.K.; Pyun, Y.R.; Kim, Y.S. Effects of pH and dissolved oxygen on cellulose production by Acetobacter xylinum BRC5 in agitated culture. J. Biosci. Bioeng. 1999, 88, 183-188. [CrossRef]

21. Kouda, T.; Naritomi, T.; Yano, H.; Yoshinaga, F. Effects of oxygen and carbon dioxide pressures on bacterial cellulose production by Acetobacter in aerated and agitated culture. J. Ferment. Bioeng. 1997, 84, 124-127. [CrossRef]

22. Jung, J.Y.; Khan, T.; Park, J.K.; Chang, H.N. Production of bacterial cellulose by Gluconacetobacter hansenii using a novel bioreactor equipped with a spin filter. Korean J. Chem. Eng. 2007, 24, 265-271. [CrossRef]

23. Yamanaka, S.; Watanabe, K.; Kitamura, N.; Iguchi, M.; Mitsuhashi, S.; Nishi, Y.; Uryu, M. The structure and mechanical properties of sheets prepared from bacterial cellulose. J. Mater. Sci. 1989, 24, 3141-3145. [CrossRef]

24. Gao, W.-H.; Chen, K.-F.; Yang, R.-D.; Yang, F.; Han, W.-J. Properties of bacterial cellulose and its influence on the physical properties of paper. BioResources 2010, 6, 144-153.

25. Santos, S.M.; Carbajo, J.M.; Gómez, N.; Quintana, E.; Ladero, M.; Sánchez, A.; Chinga-Carrasco, G.; Villar, J.C. Use of bacterial cellulose in degraded paper restoration. Part II: Application on real samples. J. Mater. Sci. 2016, 51, 1553-1561. [CrossRef]

26. Santos, S.M.; Carbajo, J.M.; Gómez, N.; Quintana, E.; Ladero, M.; Sánchez, A.; Chinga-Carrasco, G.; Villar, J.C. Use of bacterial cellulose in degraded paper restoration. Part I: Application on model papers. J. Mater. Sci. 2016, 51, 1541-1552. [CrossRef]

27. Nishi, Y.; Uryu, M.; Yamanaka, S.; Watanabe, K.; Kitamura, N.; Iguchi, M.; Mitsuhashi, S. The structure and mechanical properties of sheets prepared from bacterial cellulose Part 2 Improvement of the mechanical properties of sheets and their applicability to diaphragms of electroacoustic transducers. J. Mater. Sci. 1990, 25, 2997-3001. [CrossRef]

28. Shah, J.; Malcolm Brown, R. Towards electronic paper displays made from microbial cellulose. Appl. Microbiol. Biotechnol. 2005, 66, 352-355. [CrossRef] [PubMed]

29. Johnson, D.; Winslow, A. Bacterial cellulose has potential application as new paper coating. Pulp Pap. 1990, 64, 105-107.

30. Johnson, D.C.; LeBlanc, H.A.; Neogi, A.N. Bacterial cellulose as surface treatment for fibrous web. U.S. Patent 4,861,427A, 29 August 1988.

31. Watanabe, K.; Tabuchi, M.; Morinaga, Y.; Yoshinaga, F. Structural features and properties of bacterial cellulose produced in agitated culture. Cellulose 1998, 5, 187-200. [CrossRef]

32. Evans, R.; Wallis, A.F.A. Cellulose molecular weights determined by viscometry. J. Appl. Polym. Sci. 1989, 37, 2331-2340. [CrossRef]

33. ASTM D4243-99, Standard Test Method for Measurement of Average Viscometric Degree of Polymerization of New and Aged Electrical Papers and Boards; ASTM International: West Conshohocken, PA, USA, 1999.

34. ISO 5263-3:2004, Pulps_Laboratory Wet Disintegration-Part 3: Disintegration of Mechanical Pulps at $>85^{\circ} \mathrm{C}$; International Organization for Standardization: Geneva, Switzerland, 2004.

35. ISO 5269-2:2004, Pulps-Preparation of Laboratory Sheets for Physical Testing-Part 2: Rapid-Köthen Method; International Organization for Standardization: Geneva, Switzerland, 2004.

36. ISO 187:1990, Paper, Board and Pulps-Standard Atmosphere for Conditioning and Testing and Procedure for Monitoring the Atmosphere and Conditioning of Samples; International Organization for Standardization: Geneva, Switzerland, 1990.

37. ISO 536:2012, Paper and board -Determination of Grammage; International Organization for Standardization: Geneva, Switzerland, 2012.

38. ISO 1924-3:2005, Paper and Board-Determination of Tensile Properties-Part 3: Constant Rate of Elongation Method (100 mm/min); International Organization for Standardization: Geneva, Switzerland, 2005.

39. ISO 1974:2012, Paper-Determination of Tearing Resistance-Elmendorf Method; International Organization for Standardization: Geneva, Switzerland, 2012. 
40. Kuo, C.-H.; Chen, J.-H.; Liou, B.-K.; Lee, C.-K. Utilization of acetate buffer to improve bacterial cellulose production by Gluconacetobacter xylinus. Food Hydrocolloids 2016, 53, 98-103. [CrossRef]

41. Shibazaki, H.; Kuga, S.; Okano, T. Mercerization and acid hydrolysis of bacterial cellulose. Cellulose 1997, 4, 75-87. [CrossRef]

42. Immergut, E.H.; Ranby, B.G.; Mark, H.F. Recent work on molecular weight of cellulose. Ind. Eng. Chem. 1953, 45, 2483-2490. [CrossRef]

43. Zahan, K.A.; Pa'e, N.; Muhamad, I.I. Process parameters for fermentation in a rotary disc reactor for optimum microbial cellulose production using response surface methodology. BioResources 2014, 9, 1858-1872. [CrossRef]

44. Tahara, N.; Tabuchi, M.; Watanabe, K.; Yano, H.; Morinaga, Y.; Yoshinaga, F. Degree of polymerization of cellulose from Acetobacter xylinum BPR2001 decreased by cellulase produced by the strain. Biosci. Biotechnol. Biochem. 1997, 61, 1862-1865. [CrossRef] [PubMed]

45. Surma-Ślusarska, B.; Danielewicz, D.; Presler, S. Properties of composites of unbeaten birch and pine sulphate pulps with bacterial cellulose. Fibers Text. East Eur. 2008, 127-129.

(C) 2017 by the authors. Licensee MDPI, Basel, Switzerland. This article is an open access article distributed under the terms and conditions of the Creative Commons Attribution (CC BY) license (http:/ / creativecommons.org/licenses/by/4.0/). 